\title{
GRINDABILITY SOFT-SENSORS BASED ON LITHOLOGICAL COMPOSITION AND ON-LINE MEASUREMENTS
}

\author{
A. CASALI $^{\S}$, G. GONZALEZ" \\ C. PEREZ ${ }^{\uparrow}$ and R. VARGAS ${ }^{\dagger}$
}

${ }^{8}$ Mining Eng. Dept., University of Chile, Av. Tupper 2069, Santiago, Chile. E-mail: acasali@ cec.uchile.cl I Electrical Eng. Dept., University of Chile Av. Tupper 2007, Santiago, Chile

${ }^{\dagger}$ CODELCO-Chile, Andina Division, PO Box 6A, Los Andes, Chile

(Received 31 January 2001; accepted 17 April 2001)

\begin{abstract}
The grinding efficiency evaluation can be performed through the comparison of the operational work index with the ore work index Wi. In this work, the development of an ore grindability softsensor (ESTMOL) is presented. The ore work index is estimated on the basis of its lithological composition. Also addressed is the experimental development of a lithological composition sensor (ACOLITO) for ores on a conveyor belt. The lithological composition is determined from image analysis on samples obtained by a color video camera. Finally, a global operational work index for a complete grinding section is defined here, and its on-line estimation (PREDIMOL) is addressed, including the required soft-sensors to overcome the measurement problems. The experimental work is done with samples obtained from the CODELCO - Andina grinding plant. All the sensors have given up to now good results. (O) 2001 Elsevier Science Ltd. All rights reserved.
\end{abstract}

\section{Keywords}

Artificial intelligence; on-line analysis; grinding; neural networks; modelling

\section{INTRODUCTION}

The concept of operating work index, Wiop, has been used to evaluate the efficiency of a grinding circuit (Rowland, 1973). Work indices obtained from operating data on any mill can be compared to grindability test results. The operating work index, Wiop, can be obtained using Bond's equation by defining $\mathrm{W}$ as the specific energy being used (power draw / new feedrate), $\mathrm{F}_{80}$ and $\mathrm{P}_{80}$ as the actual feed and product $80 \%$ passing sizes, and Wi as the operating work index, Wiop. Once corrected for the particular application and equipment - related factors, Wiopc, can be compared on the same basis to grindability test results. This allows a direct comparison of grinding efficiency. Ideally Wi should be equal to Wiopc and grinding efficiency should be unity (Napier-Munn, 1996). However, results for ball mills in rod - ball mill circuits (Rowland, 1973) show variation of the ratio Wiopc/Wi from 0.78 to 1.29. A mill can be operating efficiently but because of the influences of classifier efficiency, ball size distribution, etc., this ratio can vary from 1 .

The operational work index can be used to evaluate the grinding operational efficiency or even to determine the optimal distribution of feed ore among parallel grinding sections. The efficiency evaluation 
can be performed through the comparison of the operational work index with the ore work index Wi. Another option is to observe the trend exhibited by the operational work index.

In the case of ore grindabilities, the usual practice is to determine the Bond work index, by testing ore samples in the laboratory. This is done occasionally through experimental campaigns, or at the most with a low frequency. In any case, the frequency at which this information is obtained does not allow the operational adaptation to a variable feed and is only suitable for performing off-line process analysis, with significant delays.

The different rock types determine several important process parameters, such as the ore grindability. It could be possible then to estimate the ore work index, based on its lithological composition. The lithological composition of the ore fed to a grinding plant is only estimated off-line from the geological studies and mine planning, both are done with low periodicity (monthly). Since this information is variable and only referential, the real feed composition - at least on a day by day basis - is unknown. To overcome this problem, on-line sensors are required to determine the lithological composition of the ore. Most of the existing studies (Marschallinger, 1997; Oestreich, 1995) deal with the on-line determination of mineral composition, but have not attempted to determine on-line the ore lithological composition. The only exception is the work done by the authors of this paper (Casali, 2000; Perez, 1999).

The determination of the operational work index requires the measurement of the feed and product size distribution, the fresh ore feedrate and the power draw. The on-line measurements of the fresh ore feedrate and the power draw are usually available. In some occasions also the product size measurement is available, but almost never the feed size. For this reason, the operational work index is determined only with occasional sampling campaigns and with time delays, which are an impediment for taking opportune corrective actions. A new approach to overcome this problem has been presented previously by the authors (González, 2000).

In this work, the experimental development of a lithological composition sensor (ACOLITO) for ores on a conveyor belt is presented. Also addressed is the development of an ore grindability soft-sensor (ESTMOL), where the ore work index is estimated on the basis of its lithological composition. Finally, a global operational work index for a complete grinding section is defined here, and its on-line estimation (PREDIMOL) is addressed, including the required soft-sensors to overcome the measurement problems. The general procedure proposed to evaluate the grinding operational efficiency, which is based on the sensors developed in this work, is shown in Figure 1.

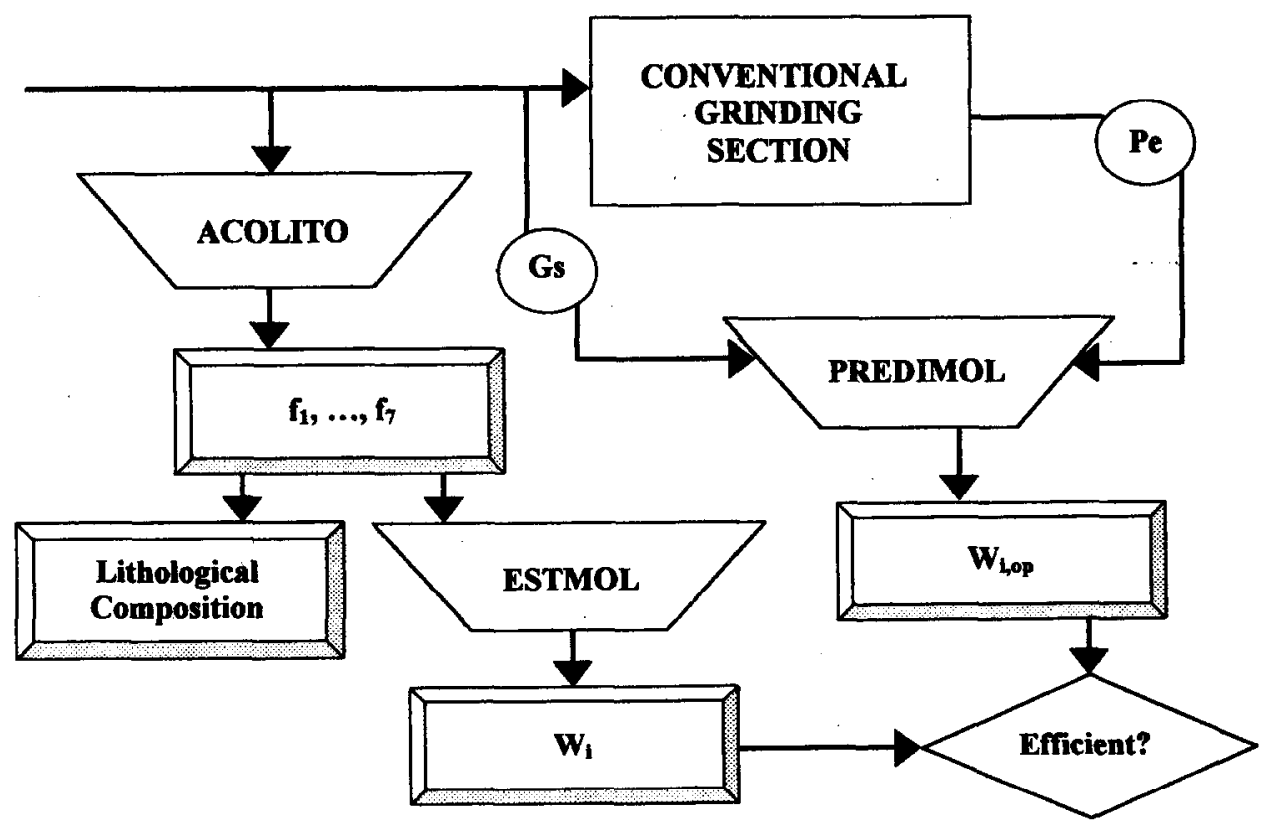

Fig.1 Grinding efficiency estimation procedure. 


\section{LITHOLOGICAL COMPOSITION SENSOR VIA IMAGE ANALYSIS (ACOLITO)}

The experimental work has been done using ore samples taken from the CODELCO-Andina Copper Mine. The Andina ore is composed of several types of rocks that can be grouped in the seven lithological classes considered for this work (see Table 1). Sub-samples of the ore were obtained, each one consisting of a single class, weighing $50 \mathrm{Kg}$ aprox. and having a particle size of $100 \%-17.8 \mathrm{~cm}+3.8 \mathrm{~cm}(-7 "+11 / 2)$. Color digital images were then obtained with a conventional CCD-NTSC camera and a frame grabber.

TABLE 1 Lithological classes

\begin{tabular}{|c|c|}
\hline Class & Lithology \\
\hline 1 & Turmaline Breccia, BxT \\
2 & Other Breccias, BxTo \\
3 & Porphyritic Dykes, PDL \\
4 & Dacitic Diatreme, CHDA \\
5 & Granodiorites, GDCC \\
6 & Andesite, AN \\
7 & Riolotic Diatreme, CHRiol \\
\hline
\end{tabular}

Two databases were constructed. One of them corresponding to single class images, of 760 digital images, each one showing between 20 and 40 rocks, in BMP format and $640 \times 480$ pixels. Another database, of 900 digital images, was constructed with mixed classes images. All images were segmented to produce a total of 5936 isolated rocks in the first database and 5205 in the second one. Both databases were separated randomly to generate the training and testing sets, as shown in Table 2.

TABLE 2 Training and testing vectors per lithological class

\begin{tabular}{|c|c|c|c|c|}
\hline \multirow{2}{*}{ Lithological class } & \multicolumn{2}{|c|}{ Single class images } & \multicolumn{2}{c|}{ Mixed classes images } \\
\cline { 2 - 5 } & $\begin{array}{c}\text { Training } \\
\text { vectors }\end{array}$ & Testing vectors & $\begin{array}{c}\text { Training } \\
\text { vectors }\end{array}$ & Testing vectors \\
\hline BxT & 637 & 319 & 458 & 916 \\
BxTo & 586 & 294 & 201 & 402 \\
PDL & 460 & 230 & 170 & 340 \\
CHDA & 638 & 320 & 132 & 264 \\
GDCC & 505 & 253 & 406 & 812 \\
AN & 522 & 261 & 287 & 574 \\
CHRiol & 607 & 304 & 81 & 162 \\
\hline Total & 3955 & 1981 & 1735 & 3470 \\
\hline
\end{tabular}

The identification method (see Figure 2) assigns each rock to a lithological class. This method consists of two main stages: (i) the feature extraction stage and (ii) the classification stage.

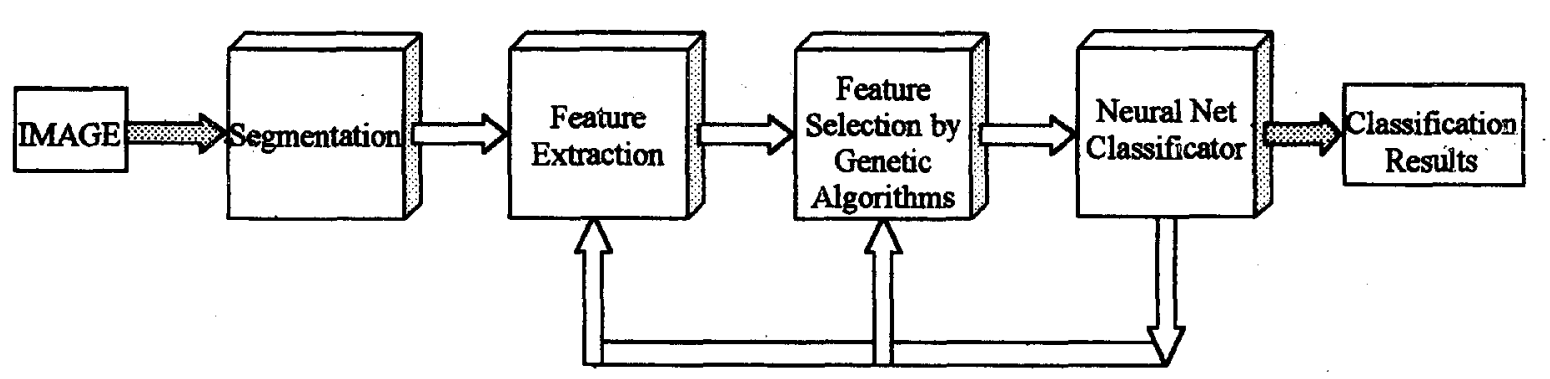

Fig. 2 Lithological classification flowsheet. 


\section{Feature extraction stage}

The feature extraction stage consists of a sequence of image acquisition, digital preprocessing and segmentation of each image (see Figure 3 ) to isolate individual rocks in a sample. Several algorithms to extract features from each rock are then applied. A total of 667 features were measured for each rock, including geometric, texture and color measurements.

From the binary image, several geometric features are obtained such as area, perimeter, area perimeter ratio, elongation ratio, mean radius, mean radius variance, mean radius variance to mean radius ratio, inertial moment to squared mean radius ratio, diameter deviation, areal shape factor, rugosity, angularity, angularity deviation and curvatures. Angularity, for example, is defined as the average angle of the successive tangents to each rock, as it is shown in Figure 4.

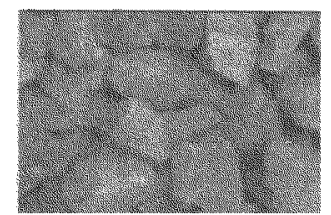

(a)
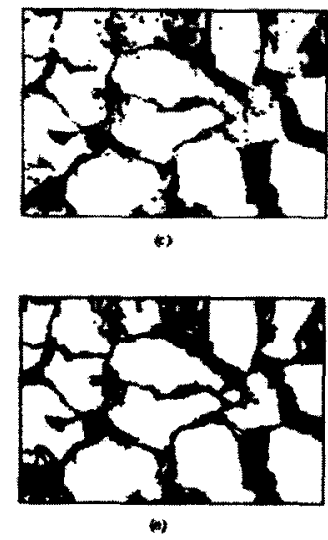

(4)

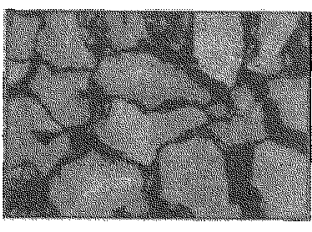

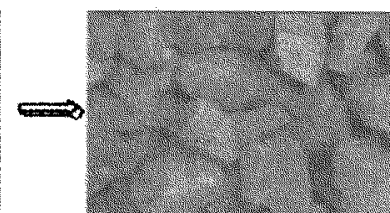

๑)
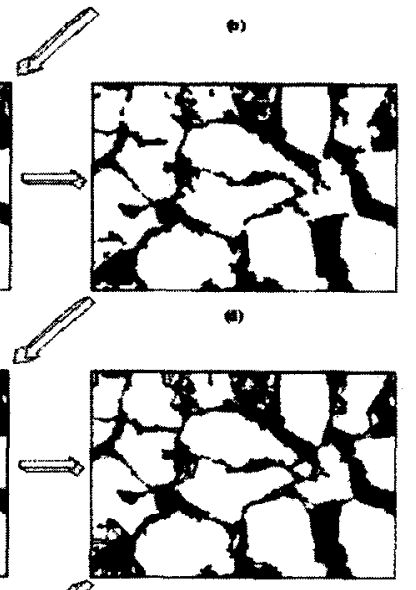

Fig.3 Segmentation sequence: (a) initial image, (b) low pass filtering, (c) binarization, (d) noise filtering, (e) erosion, ( $f$ ) segmentation and $(g)$ final image.

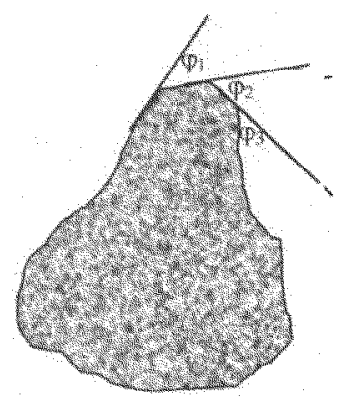

Fig. 4 Successive tangents to measure rock angularity. 
Texture features and color measurements were also obtained using each one of the 4 components of the color image: R, G, B and luminance, some of such measurements were texture from Laplacian operators (as an example, see Figure 5), texture from grid analysis, energy, contrast, entropy, homogeneity, histogram mode, mean intensity, intensity standard deviation, intensity standard deviation to mean intensity ratio, mode intensity, width of the histogram at different thresholds, third and fourth order geometrical moments, geometric center deviation (only for R, G and B components) and inertial moment to squared mean radius ratio. Some of these measurements were also obtained from the normalised $R, G$, and $B$ components. Finally, using simultaneously the R, G and B components, the color of each segmented rock is determined.

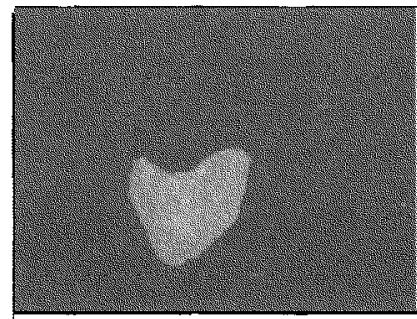

(a)

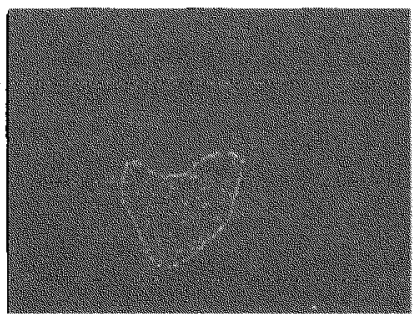

(c)

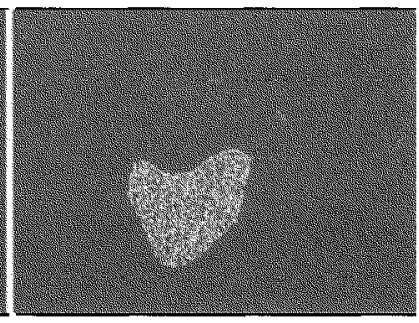

(b)

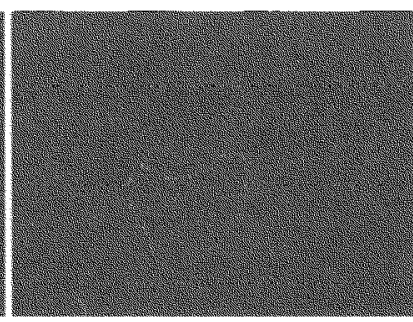

(d)

Fig.5 Granodiorite texture from Laplacian operators: (a) initial image, (b) edge detection, (c) edge detection at $20 \%$ threshold and (d) edge detection at $50 \%$ threshold.

\section{Classification stage}

The classification stage is performed using a neural network. The neural classifier is composed of $\mathrm{N}$ input units, 20 hidden units and 7 output units. Each output corresponds to one of the lithological classes. The $\mathbf{N}$ value depends on the number of features selected for evaluation. As an example, the architecture of an $\mathrm{N}$ $20-7$ neural network is presented in Figure 6.

The output from each neuron is a sigmoidal function of the weighted sum of its entries. The neural classifier is trained, adjusting the weight factors $w_{i}$, using the R-Prop algorithm (Hannan, 1997). The rule to update the weights is given by the following equation:

$$
\Delta w_{i}(t)=\delta_{i}(t) \operatorname{sign}\left(G_{i}(t)\right)-\varepsilon w_{i}(t)
$$

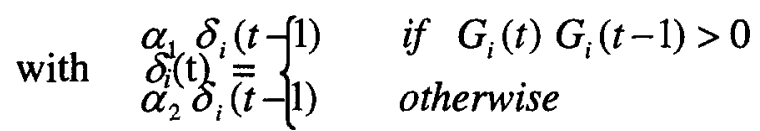

where: $G_{i}$ is the error gradient, $\delta_{i}$ is the learning step magnitude of weight i, $\alpha_{1}$ is the accelerating factor of the learning step $\left(\alpha_{1}>1\right), \alpha_{2}$ is the breaking factor of the learning step $\left(0<\alpha_{2}<1\right)$, and $\varepsilon$ is the attenuating factor $(0<\varepsilon<1)$. The values of these parameters used for the neural classifier training were: $\alpha_{1}=1.25, \alpha_{2}$ $=0.5$ and $\varepsilon=0.0001$. 


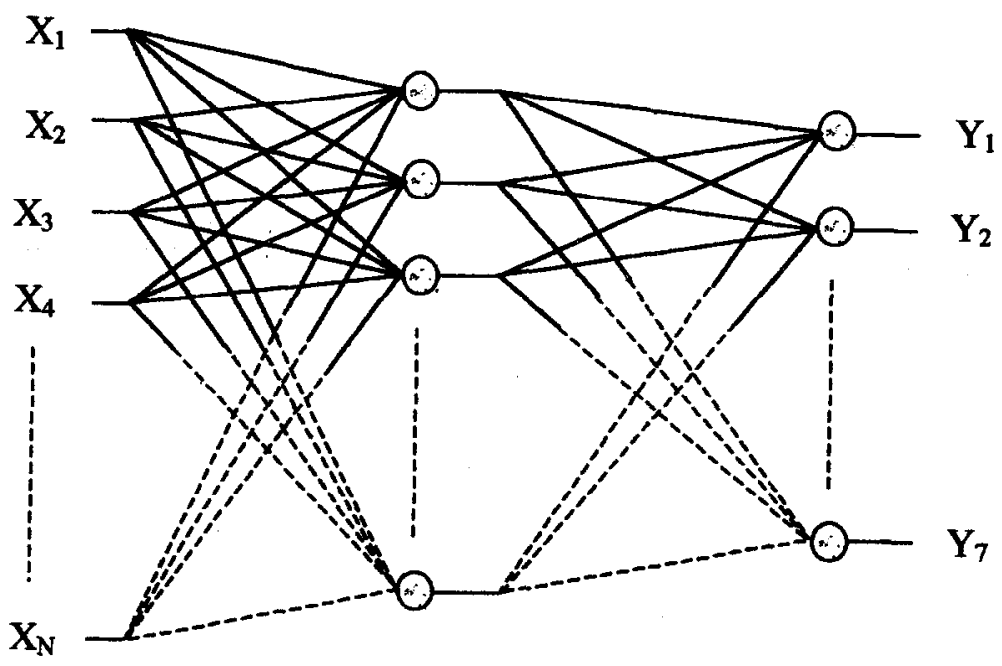

Fig.6 Neural network architecture

A genetic algorithm is used to select the set of features, which optimizes the classification performance of the neural network, while minimizing the number of selected features (number of inputs to the classifier). A standard genetic algorithm (Ming-Yeong, 1997; Perez, 1997) is used. A vector with 1s or 0s is generated for all the inputs to the neural classifier. A "1" codes a feature selected as input to the neural classifier and a " 0 " codes a feature that is not selected as input.

The genetic algorithm uses a population of 20 couples of individuals. The four steps of the genetic algorithm are as follows: (a) Generation of the initial population by randomly assigning $1 \mathrm{~s}$ or 0 s to each of the inputs to the neural classifier. (b) Training each network by back propagation with the set of training patterns and evaluating with the testing set. (c) The fitness value (fitness average) for a given network is calculated using equation 2. (d) The evolutive stage is composed of proportional selection, two-point crossover and mutation operators, applied to the chromosomes of the input population to produce a new generation of individuals.

$\operatorname{Fitness}(x)=c(x)-\alpha \frac{N(x)}{N_{\max }}$

Where: Fitness $(x)$ is the fitness of individual $x$, i.e. the fitness of a particular set of selected features, $c(x)$ is the correct classification rate for individual $x$ on the testing set, $\alpha$ is a proportional parameter in the penalising factor which penalises large number of inputs (small value between 0 and 0.1 ), $N(x)$ is the selected number of inputs to the classifier (number of features) taken from the total number of features, $N_{\max }$, for individual $x$.

An intermediate population, $\mathrm{Y}$, is created by crossover between each individual $\mathrm{x}$ and another individual chosen randomly. Each bit in the string of the new individual is generated by copying with probability 0.33 , in the first parent, the corresponding bit from the second parent (Perez, 1999).

Each bit in all individuals of the population $Y$ is mutated with a small probability (Perez, 1997). The probability of mutation is dependent on the entropy of that bit in the population.

Table 3 shows the percentages of correct classification obtained, in 5 different tests, with the lithological sensor. Test 1 considers features extracted from the whole image while tests 2 to 5 consider features extracted from segmented rocks. For example in test 1 (single class images), 70 inputs were selected after 16 generations by the genetic algorithm obtaining a $91.3 \%$ of correct classification. The others tests were made with: mixed classes images (test 2), mixed and single classes images (tests 3 and 5) and single classes images (test 4). In the cases of tests 4 and 5, an additional feature, the color vector, was considered. 
TABLE 3 Lithological classification results

\begin{tabular}{|c|c|c|c|}
\hline Test & Generations & Selected features & $\begin{array}{c}\text { Correct classification } \\
{[\%]}\end{array}$ \\
\hline 1 & & & 91.3 \\
2 & 16 & 70 & 76.3 \\
3 & 100 & 35 & 61.1 \\
4 & 100 & 88 & 79.8 \\
5 & 80 & 252 & 64.7 \\
\hline
\end{tabular}

Figure 7 shows the classification performance for the testing set 1, using the selected 70 inputs.

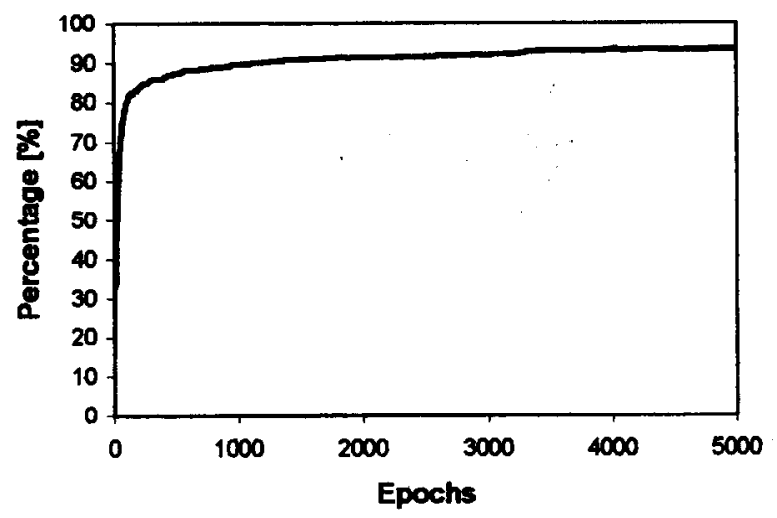

Fig.7 Lithological sensor classification performance. Test 1: 70 genetically selected inputs.

\section{Transformation from areal to weight distribution}

The lithological compositions were determined on a two dimensions basis (plane) and the information is required on a three dimensions (volumetric or weight) basis. In this work, a simple transformation from areal to weight distribution method was used.

Starting from the well known procedure that allows the transformation from surface to weight distribution and considering the relation between surface and projected area, it can be shown that the transformation from areal (projected) distribution to weight distribution can be expressed as follows,

$$
f_{3 j}=\frac{\left(\frac{\alpha_{V}}{\alpha_{s}}\right)_{j}\left(\frac{S}{A}\right)_{j} \rho_{j} \bar{d}_{j} f_{2 j}}{\sum_{i=1}^{7}\left(\frac{\alpha_{V}}{\alpha_{s}}\right)_{i}\left(\frac{S}{A}\right)_{i} \rho_{i} \bar{d}_{i} f_{2 i}}
$$

where, for rocks belonging to lithology " $\mathrm{j}$ ":

$$
\begin{aligned}
& f_{3 \mathrm{j}}=\quad \text { mass fraction. } \\
& \left(\frac{\alpha_{v}}{\alpha_{S}}\right)_{j}=\text { ratio between volume and surface area shape factors. } \\
& \left(\frac{S}{A}\right)_{j}=\text { ratio between surface and projected area. } \\
& \rho_{j}=\quad \text { density. }
\end{aligned}
$$


$\bar{d}_{j}=\quad$ areal weighted average diameter.

$f_{2 \mathrm{j}}=\quad$ areal (projected) fraction.

From the Heywood shape factors equations (Kelly, 1982), it is possible to express the ratio between the volume and surface area shape factors as follows:

$$
\left(\frac{\alpha_{S}}{\alpha_{V}}\right)_{j}=\frac{C_{1 j} R_{F j} \sqrt{R_{E j}}}{\left(\alpha_{V a e}\right)_{j}}+\frac{C_{2 j}\left(\alpha_{V a c}\right)_{j}^{1 / 3}\left(R_{E j}+1\right)}{\left(R_{F j}\right)^{1 / 3}+\sqrt{R_{E j}}}
$$

where, for each lithology j: $R_{E j}=$ length / breadth (elongation ratio), $R_{F j}=$ breadth / thickness (flatness ratio) and $\alpha_{V a e j}=$ equidimensional volumc shape factor. $C_{l j}$ and $C_{2 j}$ are constants to be adjusted.

This new procedure was tested with a composite (known lithological composition) disposed randomly on a multi layer. The required measurements were made and the transformation method applied. The results are shown in Table 4.

TABLE 4 Experimental and estimated mass fractions

\begin{tabular}{|c|c|c|c|}
\hline $\begin{array}{c}\text { Lithological } \\
\text { Class }\end{array}$ & $\begin{array}{c}\text { Mass fraction } \\
\boldsymbol{f}_{\mathbf{3 i}}[\boldsymbol{\%}]\end{array}$ & $\begin{array}{c}\text { Estimated } \\
\boldsymbol{f}_{\mathbf{3 i}}[\boldsymbol{\%}]\end{array}$ & $\begin{array}{c}\text { Squared residue } \\
{[\boldsymbol{\%}]^{\mathbf{2}}}\end{array}$ \\
\hline BxT & 9.8 & 6.8 & 9.0 \\
BxTo & 17.0 & 14.8 & 4.8 \\
PDL & 17.2 & 17.6 & 0.2 \\
CHDA & 14.3 & 16.9 & 6.8 \\
GDCC & 14.5 & 13.5 & 1.0 \\
AN & 11.4 & 16.4 & 25.0 \\
CHRiol & 15.8 & 14.0 & 3.2 \\
\hline Total & 100.0 & 100.0 & 50.0 \\
\hline
\end{tabular}

The associated error, for $n=7$ lithologies, can be estimated from the sum of the squared residues (SSR $=$ 50.0 ) using equation 5 . For this testing set, the resulting error is smaller than $3 \%$.

$$
\text { Error } \approx \sqrt{\frac{S S R}{(n-1)}}
$$

\section{WORK INDEXES SOFT-SENSORS}

\section{Ore grindability soft-sensor (ESTMOL)}

The information supplied by the lithological composition sensor, i.e., the fraction of each lithological class in the composite, may now be used as an input to the ore grindability soft-sensor which estimates the ore work index (Wi). To determine the model for this soft-sensor, both the structure (equation 6) and its parameters are determined using data, corresponding to the ore work index and the lithological composition per month, obtained from the Andina mine plan for a period of 46 months.

$$
W i=b_{1} f_{1}+b_{2} f_{2}+b_{3} f_{3}+b_{4} f_{5}+b_{5} f_{6}+b_{0}
$$

This model is of the moving average type, where the inputs are given by the weight fraction, $f_{j}$, of each lithological class " $j$ ". The parameters $\left\{b_{j}\right\}$ of this model were determined using stepwise regression for data sets of Wi and $\mathrm{f}_{\mathrm{j}}$ in a moving window of 12 months. Figure 8 shows the prediction obtained using equation 6 for month 13 following each 12 months data set. 


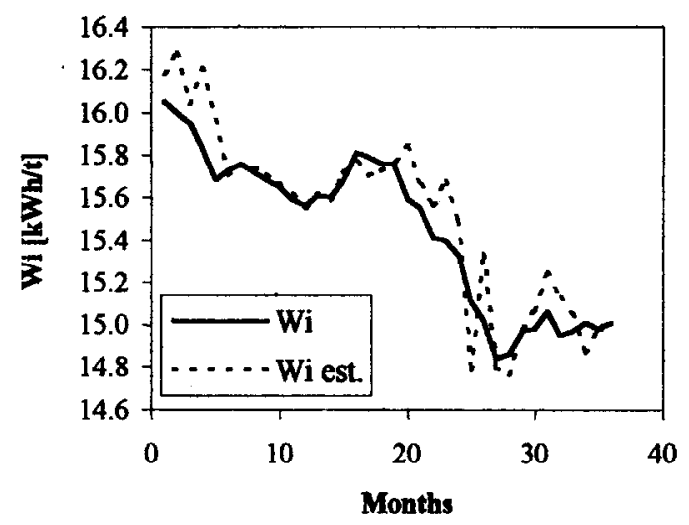

Fig.8 Experimentally determined and estimated (ESTMOL) work indexes.

\section{Operational work index soft-sensor (PREDIMOL)}

Figure 9 shows a schematic diagram of one of the grinding circuits of Andina plant, from which the data for this paper has been obtained.

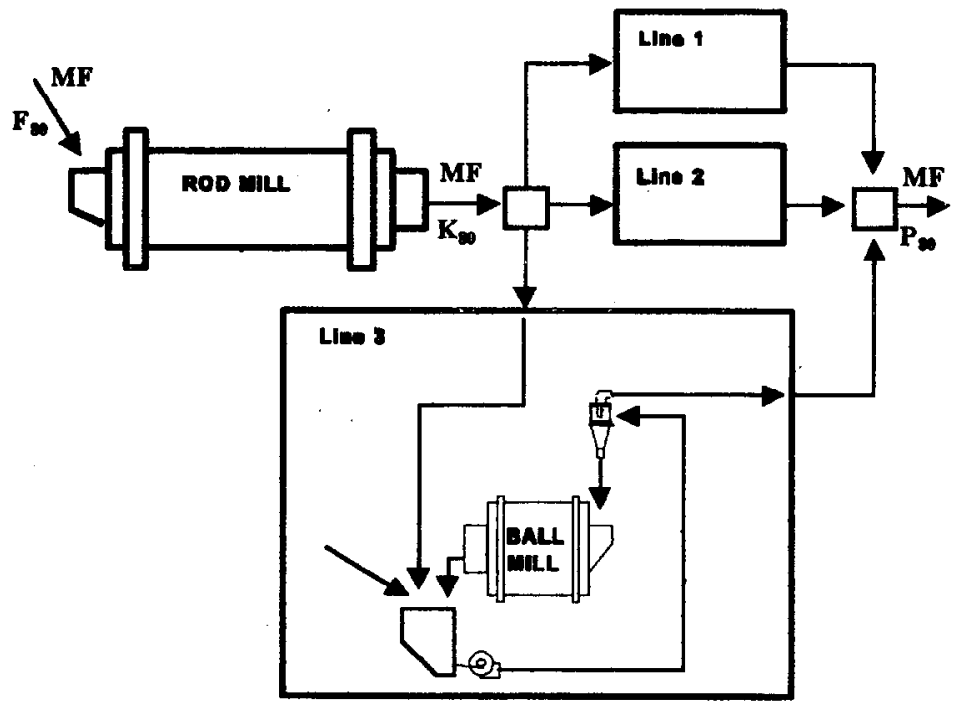

Fig.9 Two stages grinding circuit flowsheet.

In Figure 9, MF is the steady state ore flowrate. $F_{80}, K_{80}$ and $P_{80}$ are the feed, intermediate and product $80 \%$ passing sizes respectively.

The operational work indexes: $W_{i o R}$ for the rod mill and $W_{i o B j}$ for each ball mill section, are given by (Rowland, 1973):

$$
W_{i o R}=\frac{P_{R}}{11.02 M F C_{R}\left(\frac{1}{\sqrt{K_{80}}}-\frac{1}{\sqrt{F_{80}}}\right)}, W_{i o B j}=\frac{P_{B j}}{11.02 M F_{j} C_{B}\left(\frac{1}{\sqrt{P_{80}}}-\frac{1}{\sqrt{K_{80}}}\right)}
$$

$P_{R}$ and $P_{B j}$ are the power draws for the rod mill and for each ball mill $\mathrm{j}(\mathrm{j}=1,2,3)$, respectively. $C_{R}$ and $C_{B}$ are particular application and equipment-related factors, depending on the geometry of the mills, the type of 
grinding and the size reduction range (constant for a given application). For the grinding plant treated here, $C_{R}=1.236$ and $C_{B}=0.922$.

A global operational work index $W_{\text {iog }}$ has been defined (González, 2000) for the plant shown in Fig. 1, assuming an equivalent unitary ball mill circuit (i.e., having one ball mill), as follows,

$$
W_{\text {iog }}=\frac{P_{T}}{11.02 M F C_{B E}\left(\frac{1}{\sqrt{P_{80}}}-\frac{1}{\sqrt{F_{80}}}\right)} \text {, }
$$

where $P_{T}$ is the total power drawn by the four mills and $C_{B E}=0.857$ (González, 2000).

Of the four variables that determine the global operational work index (equation 8), the power draw $P_{T}$ is the sum of reliable on-line electrical measurements. The on-line measurement of the plant throughput, $M F$, is very important for assessing the plant performance, so it is usually a high availability exact and precise measurement.

In some cases a sensor for measuring $P_{80}$ is installed in a plant, even though its measurement may not have the availability of the power and ore flow measurements. But the corresponding sensor for measuring particle size at the feed end of the grinding plant is not available. In either case then it becomes necessary to infer $F_{80}$ always and to infer $P_{80}$ whenever the particle size sensor fails, it is removed for maintenance, or simply because it is not installed. Soft-sensors for inferring particle size at hydrocyclone overflow have been reported in the literature (Casali, 1998).

In order to determine the requirements of the soft-sensors that must be used to infer these variables, the sensitivities ( $\mathrm{S}_{\mathrm{WF}}$ and $\mathrm{S}_{\mathrm{WP}}$ ) of the operational work index $W_{i o g}$ with respect to $F_{80}$ and $P_{80}$ have been found (González, 2000) taking partial derivatives of equation 8 . These sensitivities were evaluated using data collected from the Andina grinding plant (Figure 9) and the following results were obtained: $S_{\mathrm{WF}}=$ $-0.1084, S_{\mathrm{WP}}=0.608$ and $\mathrm{S}_{\mathrm{WP}} / \mathrm{S}_{\mathrm{WF}}=-5.61$, showing a much higher sensitivity with respect to $P_{80}$ than to $F_{80}$.

An analysis of the plant data during a period of 46 months shows the statistics for $F_{80}$ and $P_{80}$ given in Table 5 .

TABLE 5 Statistics for $F_{80}$ and $P_{80}$ over a 46 months period

\begin{tabular}{|c|c|c|}
\hline & $\begin{array}{c}\text { Average } \\
{[\mu \mathrm{m}]}\end{array}$ & $\begin{array}{c}\text { Standard deviation } \\
{[\mu \mathrm{m}]}\end{array}$ \\
\hline $\mathrm{F}_{80}$ & 9,774 & 379 \\
$\mathrm{P}_{80}$ & 310 & 45 \\
\hline
\end{tabular}

For a change of $\mathrm{F}_{80}$ corresponding to three times its standard deviation, around its average value, can be found (González, 2000) that Wiog changes in around 1.26\%, i.e., quite small. As a result, the soft-sensor for $\mathrm{F}_{80}$, is the simplest of all, since it will be equal to the average of $\mathrm{F}_{80}$ during the period considered. Then the average of $F_{80}$ will be used in following periods when it is not measured, supposing it remains fairly fixed, until new laboratory measurements are obtained and the average value may be updated.

For changes of $\mathbf{P}_{80}$ corresponding to three standard deviations, around its average value, can be found (González, 2000) that Wiog changes in around 29.4\%. This is a rather large change, so that the average $P_{80}$ may not be an adequate estimator of $\mathrm{P}_{80}$ and a more complex soft-sensor is needed.

For the design of a soft-sensor for $\mathrm{P}_{80}$ only the very reliable measurements $\mathrm{P}_{\mathrm{T}}$ (power draft of the mills), and MF (the feed ore flow) have been used. This reliability criterion restricts the candidate measurements as opposed to the soft-sensors determined by (Casali, 1998). The resulting soft-sensor is given by 


$$
P_{80} e s t(t)=a_{0}+a_{1} M F(t)+a_{2} P_{T}(t)
$$

Figure 10 shows a test of the prediction capabilities of this soft-sensor.

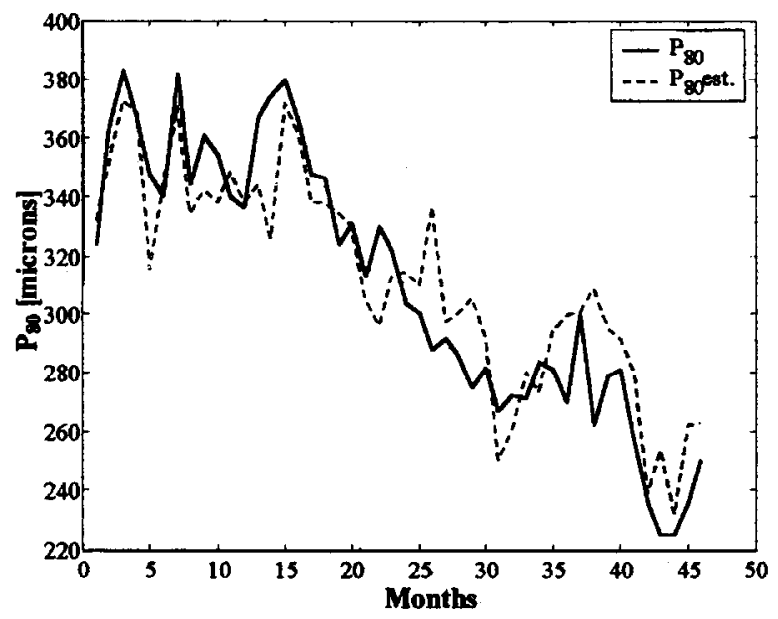

Fig.10 Soft-sensor for $\mathrm{P}_{80}$ compared with actual $\mathrm{P}_{80}$.

Then for the determination of $\mathrm{W}_{\mathrm{iog}}$, the measurement of $\mathrm{P}_{80}$ (if it is available) or the soft-sensor prediction can be used. In Figure 11 a test of the prediction capability for $\mathrm{W}_{\mathrm{iog}}$ is shown using the fixed value (average) for $F_{80}$ and $P_{80}$ est given by the soft-sensor.

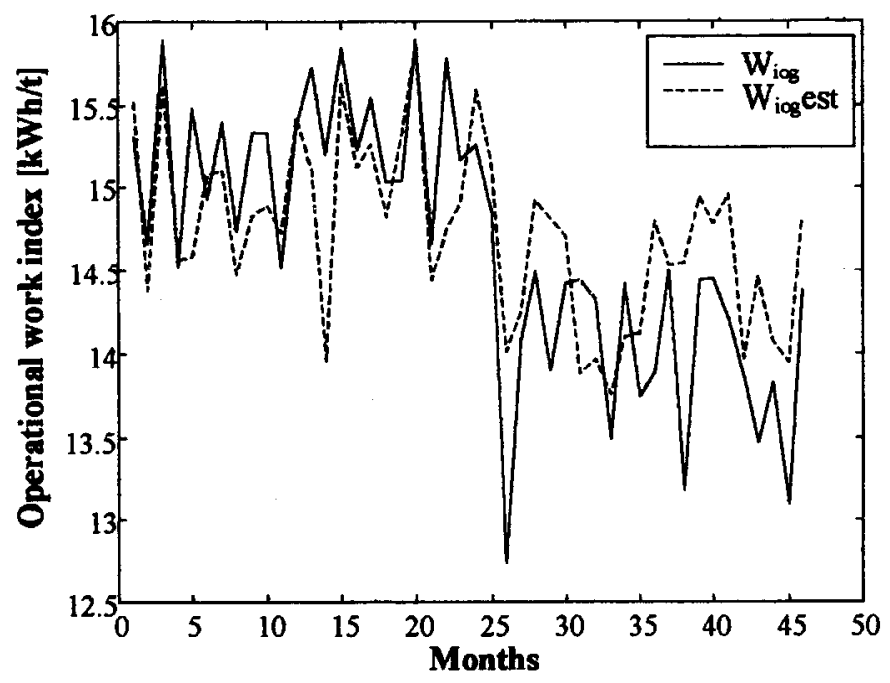

Fig.11 Actual operational work index $W_{\text {iog }}$ and its estimated value $W_{\text {iog }}$ est using the average $F_{80}$ and the $P_{80}$ soft-sensor.

\section{CONCLUSIONS}

The lithological composition sensor (ACOLITO) developed to estimate the lithology of the ore on a belt conveyor has given up to now good results. The image analysis with the segmentation and the feature extraction process, followed by the classification stage using a neural network has shown a good performance. The genetic algorithm proved to be an excellent tool for reducing the number of inputs to the classifier, without significant losses in the correct classification results. 
The results obtained with the ore grindability soft-sensor (ESTMOL), using mine plan data, have shown that it is possible to obtain a good estimate of the work index based on its lithological composition.

A global operational work index for a grinding plant has been defined using Bond's equation applied to the total feed, total product and total mills power draft of a grinding plant. Based on this, an operational work index soft-sensor (PREDIMOL) was developed.

A sensitivity analysis showed that the operational work index had a small sensitivity with respect to $\mathrm{F}_{80}$, so that its average value could be used with good results. On the other hand, the sensitivity of the operational work index with respect to $P_{80}$ was not small. Therefore a soft-sensor for $P_{80}$ had to be developed and it has given good results. It has been further shown that PREDIMOL soft-sensor gives an acceptable estimation of the global operational work index.

\section{ACKNOWLEDGEMENTS}

This research was funded by CODELCO-Chile under a grant from the CODELCO / U. DE CHILE research agreement. The authors express the thanks to CODELCO - Andina Division for their valuable contribution.

\section{REFERENCES}

Casali, A., Gonzalez, G., Torres, F., Vallebuona, G., Castelli, L. and Gimenez, P., Particle size distribution soft-sensor for a grinding circuit. Powder Technology, 1998, 99, 15-21.

Casali, A., Vallebuona, G., Pérez, C., González, G. and Vargas, R., Lithological composition and ore grindability sensors, based on image analysis. In Proc. of the XXI IMPC, Rome, 2000, pp. A1(9 -16).

González, G., Perez, C., Casali, A., Vallebuona, G. and Vargas, R., Operational work index for grinding plants. In Proc. of the XXI IMPC, Rome, 2000, pp. C4(1 -7).

Hannan, J. and Bishop, J., A comparison of fast training algorithms over two real problems. In Proc. of the $V$ Int. Conf. on Artificial Neural Networks, IEEE, London, 1997, pp. 1-6.

Kelly, E. and Spottiswood, D., Introduction to Mineral Processing, 1982, Chap. 2, J. Wiley \& Sons, New York.

Marschallinger, R., Automatic mineral classification in the macroscopic scale. Computers \& Geosciences, 1997, 23 (1), pp. 119-126.

Ming-Yeong Teo, Li-Pheng Khoo and Siang-Kok Sim, Application of genetic algorithms to optimize recognition parameters. Neural Network World, 1997, (3), pp. 293-304.

Napier-Munn, T., Morrell, S., Morrison, R. and Kojovic, T., Mineral Comminution Circuits - Their Operation and Optimization, 1996, Chap. 4, JKMRC, Queensland.

Oestreich, J. Tolley, W. and Rice, D., The development of a color sensor system to measure mineral compositions. Minerals Engineering, 1995, 8 (1/2), pp. 31-39.

Perez, C. and Holzmann, C., Improvements on handwritten digit recognition by genetic selection of neural network topology and by augmented training. In Proc. of the Int. Conf. on Systems, Man \& Cybernetics, IEEE, Orlando, 1997, pp. 1487-1491.

Perez, C., Casali, A., Gonzalez, G., Vallebuona, G. and Vargas, R., Lithological composition sensor based on digital image feature extraction, genetic selection of features and neural classification. In Proc. of the Int. Conf. on Information Intelligence \& Systems, IEEE, Bethesda, 1999, pp. 236-241.

Rowland, C., Comparison of work indexes calculated from operation data with those from laboratory test data. In Proc. of the XIMPC, London, 1973, pp. 47-71.

Correspondence on papers published in Minerals Engineering is invited by e-mail to bwills@min-eng.com 